\title{
Fertility preferences and contraceptive change in developing countries
}

\author{
Bamikale J. Feyisetan \\ Population Council \\ John B. Casterline \\ Population Council
}

Follow this and additional works at: https://knowledgecommons.popcouncil.org/departments_sbsr-pgy

Part of the Demography, Population, and Ecology Commons, Family, Life Course, and Society Commons, and the International Public Health Commons How does access to this work benefit you? Let us know!

\section{Recommended Citation}

Feyisetan, Bamikale J. and John B. Casterline. 1999. "Fertility preferences and contraceptive change in developing countries," Policy Research Division Working Paper no. 130. New York: Population Council. Version of record: https://doi.org/10.2307/2648298 


\title{
Fertility Preferences and Contraceptive Change in Developing Countries
}

\author{
Bamikale Feyisetan \\ John B. Casterline
}

Bamikale Feyisetan is a Berelson Fellow and John B. Casterline is Senior Associate, Policy Research Division, Population Council.

This research is an outgrowth of the second author's participation in the project "The New Demography of the Arab Region," based at the Social Research Centre, the American University in Cairo. Support and comments from Laila ElZeini and Hoda Rashad are gratefully acknowledged. 


\begin{abstract}
Fertility has declined substantially in developing countries in the period since 1960, primarily as the result of increases in contraceptive prevalence. Little dispute is found on this point, but considerable debate has arisen about the causes of the increase in contraceptive prevalence. One unresolved issue is the causal contribution of changes in fertility desires. The sources of increase in contraceptive prevalence are analyzed in 22 countries in Latin America, Asia, and Africa in the period from the 1970s to the 1990s, using World Fertility Survey and Demographic and Health Survey data. Through regression decomposition, change in prevalence is attributed to change in fertility preferences ("composition") and change in rates of use within preference categories ("rates"). The rates component can be viewed as the increase in prevalence resulting from increased implementation of preferences. Two fertility-preference variables are examined, the desire for another birth and the difference between actual and ideal family size. The rates component dominates in all 22 countries, ranging between 75 percent and 90 percent in most of the countries. In only two countries does the composition component exceed 25 percent. The results refute demand-side explanations that ignore or dismiss the potential for substantial increase in prevalence through the satisfaction of existing demand. Although changes in fertility preferences account for a small proportion of the increase in prevalence, this component weighs more heavily in societies at the early stages of transition and in sub-Saharan Africa. In these settings, declining demand for children has been a significant underlying cause of increases in contraceptive prevalence, and further declines in demand are required if the transition is to proceed to replacement-level fertility.
\end{abstract}

This material may not be reproduced without written permission from the authors. 
Since 1960, fertility has declined substantially in developing countries. Increased practice of contraception is the chief direct cause of this historic development. Little dispute has occurred on this point, but considerable disagreement has arisen about the causes of the increase in contraceptive prevalence. The various factors that have been posited as causes can be classified into two general groups, conventionally labeled "supply-side" and "demand-side" factors. The former term refers to the supply of contraceptives available to individuals, as determined by the geographical accessibility of family planning services and the cost and quality of those services. The primary, but not exclusive, focus of public and private family planning programs is this constellation of factors. The "demand-side" category encompasses all factors that affect the demand for contraception. First and foremost among these factors is the desire to avoid pregnancy (either temporarily or indefinitely). Demand-side factors also include social, psychic, and cultural variables that either encourage or discourage contraceptive use, which in the Easterlin synthesis model are termed the "nonaccess costs of fertility regulation" (Easterlin and Crimmins 1985). This latter set of factors, which may well be key determinants of the practice of contraception in some settings (Bongaarts and Bruce 1995; Casterline et al. 1997), has received less attention in research on trends in contraception and, in any case, typically these factors are not rigorously measured in demographic surveys. The focus of a long-running debate, therefore, has been the relative contributions of changes in the desire to avoid pregnancy (changes in desired family size and changes in birth-spacing preferences) as against changes in the supply of contraceptive services (as determined by organized family planning programs).

The debate has been highly contentious, and for good reason, because at stake is the rationale for substantial investments in family planning programs. The classic statements of demographic transition theory portray fertility decline as a direct consequence of decreased demand for children, itself a response to improved child survival and structural changes in the society that reduce the benefits and increase the costs of rearing children (Notestein 1953; Davis 1963; Hirschman 1994). Although this view fits comfortably with the mainstream of social science theory on fertility, evidence from the first fertility surveys conducted in poor countries in the 1960s suggested that the classic theory, if not incorrect, at least needed to be enlarged. The surveys revealed that large proportions of women wanted to avoid further births but were not practicing contraception (Mauldin 1965; Berelson 1966). The conclusion drawn from this evidence was that a lack of interest in curtailing fertility was by no means the only, or perhaps even the 
primary, explanation for the low levels of contraceptive prevalence in the poor countries of Asia, Africa, and Latin America. Several influential interpretations of the historical European fertility decline also stressed the causal impact of changes in the knowledge and means of practicing contraception (Knodel and van de Walle 1979; Cleland and Wilson 1987). A logical inference from this body of research is that improvements in access to contraception can, in themselves, lead to increases in contraceptive prevalence; that is, contraceptive practice can respond to changes in supply-side factors in the absence of accompanying changes in demand-side factors. This proposition presumes, of course, the existence of unsatisfied demand for contraception. This view can be held without denying that demand-side factors also make a substantial contribution to reproductive change. Indeed, few demographers argue for one set of factors at the expense of the others; rather, the consensus is that both demand-side and supply-side factors operate, and the empirical challenge is to determine the relative magnitude of the two, because this varies among settings (Freedman 1979).

The debate has continued in these general terms from the 1960s to the present. One specific and critical issue in this debate has been the meaningfulness of the data on fertility desires that are collected in demographic surveys. Hauser (1967) doubted their validity and, by implication, the validity of the "KAP-gap" and "unmet need" estimates cited from the 1960s to the present as evidence of the potential for fertility decline in the absence of increases in the desire to avoid pregnancy. The weight of the accumulated empirical research, however, is that survey data on fertility desires are valid, as assessed either at the aggregate or at the individual level (Westoff and Ryder 1977; Hermalin et al. 1979; Westoff 1990; De Silva 1991; Poo Chang and Tey 1994; Bankole and Westoff 1998). Hence the major protagonists on both sides of this debate in the 1990s have not questioned the overall validity of these data. The analysis in this paper as well starts from the premise that fertility desires are adequately measured by standard questionnaire items employed in the major international survey programs of the past three decades (the World Fertility Survey [WFS] program of the 1970s and 1980s and the Demographic and Health Survey [DHS] program of the 1980s and 1990s).

No one simple, decisive test of the relative merits of the supply-side and the demand-side arguments exists. Research can be designed, however, that yields findings 
more consistent with one or the other argument, and that is the strategy followed here. An implication of the demand-side argument is that changes in reproductive behavior are due principally to changes in fertility desires. The supply-side argument, in contrast, allows for substantial change in reproductive behavior in the absence of changes in fertility desires; in such instances, the reproductive change can come about through a more complete implementation of existing fertility desires (via use of contraceptives and other fertility-regulation practices). This is the criterion Pritchett leans on most heavily in his controversial attack on the supply-side argument (Pritchett 1994). He concludes that declines in fertility in the past three decades have been due almost entirely to declines in desired fertility, and from this and other evidence dismisses supply-side factors-family planning programs in particular-as making only the most minor contribution to recent fertility declines. Other empirical analyses have arrived at a different conclusion. Bongaarts (1992), in an analysis of DHS data collected in the late 1980s in 18 countries, shows that the implementation of fertility preferences through contraception varies by level of fertility, and from this infers that fertility decline can be attributed in part to increased implementation of preferences. In a second empirical exercise, Bongaarts (1993) decomposes fertility decline during the 1980s in 12 developing countries and calculates that on average, the increased implementation of preferences accounts for 66 percent of the observed fertility decline, a result that lends considerable credence to the supply-side argument. ${ }^{1}$

These empirical studies were an effort to assess the extent to which change in fertility and contraception can be characterized as "demand-driven." With few exceptions (for example, Bongaarts 1993), however, this research employs inappropriate or indirect analytical strategies: Cross-sectional analysis is used instead of over-time analysis, and direct measurement of key variables (fertility preferences) is absent or inadequate. These approximations and compromises are unnecessary, because more direct approaches are feasible. In the case of contraceptive practice, given the existence in many countries of two or more cross-sectional surveys conducted before and after substantial increases in contraceptive prevalence, formal decompositions of the increase in prevalence can be carried out in terms of hypothesized determinants, including fertility preferences. In this paper, available data and conventional demographic methods are used to address the 
question: What fraction of the change in contraceptive prevalence can be attributed to changes in fertility preferences?

\section{DATA AND METHODS}

Survey data collected in the period from 1975 to 1997 in 22 countries in Africa, Asia, and Latin America are analyzed and the results shown in Table 1. The selection of countries was governed by two criteria: first, the availability of two surveys from either the World Fertility Survey or Demographic and Health Survey programs, preferably spaced at least ten years apart; second, a substantial increase in contraceptive prevalence, preferably of ten percentage points or more. ${ }^{2}$ In a few instances, countries are selected that satisfy only one of these two criteria. In Uganda, the two surveys were conducted less than ten years apart, but the increase in contraceptive prevalence was substantial enough to justify analysis. In Côte d'Ivoire, Senegal, and Yemen, the increase in prevalence was less than ten percentage points but represented a doubling (or greater) of the prevalence rate. In most countries, the first survey is a WFS from the late 1970s or early 1980s and the second survey is a DHS from the 1990s (or late 1980s in some instances). In all but one country (Uganda), the surveys are separated by ten or more years; in 11 countries, the gap is 15 years or more. In three countries (Brazil, Senegal, and Uganda), data from two Demographic and Health Surveys are compared, either because no WFS was conducted or, in the case of Senegal, because of noncomparable measurement of a key variable in the WFS. The standard recode file for each survey is used.

Surveys conducted under the auspices of these two programs are comparable in their basic features (Westoff and Bankole 1999). For both sets of surveys, relatively large probability samples of women of reproductive age were interviewed. ${ }^{3}$ The questionnaires for the two sets are broadly similar. Items for the two key variables in this analysis - contraceptive behavior and fertility preferences-are not identical, but they resemble each other closely enough that it is safe to assume that incomparable measurement cannot account for much of the observed differences between surveys. Some differences in the structure of the WFS and DHS questionnaires deserve mention, however, because they affected the design of this analysis. 
Table 1 Percentage of currently married women aged 15-44 using a contraceptive method at first and second surveys, and percentage-point increase in contraceptive use, 22 countries

\begin{tabular}{|c|c|c|c|c|c|}
\hline Region/country & $\begin{array}{l}\text { Date } \\
\text { of first } \\
\text { survey }\end{array}$ & $\begin{array}{c}\text { Percent } \\
\text { using } \\
\text { at first } \\
\text { survey }\end{array}$ & $\begin{array}{l}\text { Date of } \\
\text { second } \\
\text { survey }\end{array}$ & $\begin{array}{c}\text { Percent } \\
\text { using at } \\
\text { second } \\
\text { survey }\end{array}$ & $\begin{array}{c}\text { Percentage-point } \\
\text { increase in con- } \\
\text { traceptive use }\end{array}$ \\
\hline \multicolumn{6}{|l|}{ Sub-Saharan Africa } \\
\hline Côte d'Ivoire & 1980 & 3.0 & 1994 & 11.4 & 8.4 \\
\hline Ghana & 1979 & 9.9 & 1993 & 20.5 & 10.6 \\
\hline Kenya & 1978 & 6.8 & 1993 & 31.4 & 24.7 \\
\hline Senegal & 1986 & 4.8 & 1997 & 12.6 & 7.9 \\
\hline Uganda & 1988 & 4.4 & 1995 & 14.4 & 10.0 \\
\hline \multicolumn{6}{|c|}{ North Africa and West Asia } \\
\hline Egypt & 1980 & 24.6 & 1995 & 49.2 & 24.6 \\
\hline Morocco & 1980 & 20.3 & 1995 & 42.2 & 21.9 \\
\hline Tunisia & 1978 & 32.0 & 1988 & 50.7 & 18.6 \\
\hline Turkey & 1978 & 41.5 & 1993 & 64.5 & 23.0 \\
\hline Yemen & 1979 & 1.2 & 1991 & 8.3 & 7.2 \\
\hline \multicolumn{6}{|c|}{ South and Southeast Asia } \\
\hline Bangladesh & 1976 & 8.2 & 1996 & 49.0 & 40.8 \\
\hline Indonesia & 1976 & 27.8 & 1993 & 56.1 & 28.3 \\
\hline Nepal & 1976 & 2.3 & 1996 & 28.0 & 25.6 \\
\hline Philippines & 1978 & 38.7 & 1998 & 48.7 & 10.0 \\
\hline Sri Lanka & 1975 & 33.7 & 1987 & 60.7 & 27.0 \\
\hline Thailand & 1975 & 35.7 & 1987 & 67.5 & 31.8 \\
\hline \multicolumn{6}{|l|}{ Latin America } \\
\hline Brazil & 1986 & 66.9 & 1996 & 76.2 & 9.3 \\
\hline Colombia & 1976 & 42.6 & 1995 & 70.9 & 28.2 \\
\hline Dominican Republic & 1975 & 33.4 & 1996 & 63.1 & 29.7 \\
\hline Mexico & 1977 & 32.7 & 1987 & 54.5 & 21.8 \\
\hline Paraguay & 1979 & 38.6 & 1990 & 49.4 & 10.8 \\
\hline Peru & 1978 & 33.4 & 1996 & 65.1 & 31.6 \\
\hline
\end{tabular}


First, the sample for questions about contraceptive use at the time of the survey in the WFS is limited to women currently in union, whereas for the DHS, questions also were asked of never-married women (where they were interviewed) and of formerly married women. The present analysis is restricted to women currently in union (legal or consensual), which, in any case, is the conventional denominator for the contraceptive prevalence rate. A further difference is that women who perceived themselves to be no longer capable of conceiving (that is, infecund) were not asked in the WFS about contraceptive use at the time of the survey. Hence, for comparability, infecund women are classified as nonusers in both sets of surveys, with the exception of those women who are contraceptively sterilized. Note that infecund women are retained in the analysis here, so that all calculations are based on all women currently in union. To reduce the possibility of bias due to the different treatment of infecund women in the WFS and DHS questionnaires, women aged 45-49 are excluded from this analysis.

Second, the depth of measurement of the desire for another child, a key explanatory variable, differs between the two survey programs. In the DHS, women who want additional children are asked how soon they want the next child. This question permits women who want to postpone the next birth (and hence have a motive to practice contraception) to be distinguished from women who want another child relatively soon. In contrast, only a few WFS surveys included a follow-up question on how soon the next child was wanted. The analysis is thereby necessarily restricted to the demand for contraception for family-size limitation, and, as a result, this research probably understates the degree to which trends in contraceptive prevalence are a response to changes in fertility preferences. Other research suggests, however, that in most settings, increases in the desire to space children contribute far less to overall trends in contraception and fertility than do increases in the desire to limit family size (Bongaarts 1992). (Note that trends in the implementation of spacing preferences are another matter altogether. In sub-Saharan Africa, increases in the implementation of spacing preferences appear to account for a substantial fraction of recent trends in contraception [Caldwell et al. 1992].) A further difference is that in the WFS, information about this desire for another child was not asked of infecund women (just as these women were not asked about current contraceptive use). In this analysis, infecund women are grouped with women who indi- 
cated that they wanted another child, because both sets of women lack a motivation to use contraceptives for the purpose of family-size limitation. This rule is applied to data from both the WFS and the DHS surveys for consistency.

The two key variables for this analysis-contraceptive use and fertility preferences-are measured as follows: Contraceptive use has two categories: using at the time of the survey and not using. In most countries, the list of contraceptive methods are not identical in the WFS and DHS, but the differences appear to be too slight to have an impact on the results. ${ }^{4}$

The principal explanatory factor, fertility preference, is measured through two variables: the desire for additional children and the difference between the actual and ideal number of children. The construction of the two variables is described in turn. Desire for additional children has two categories: wanting more and not wanting more. For nonpregnant women, classification is straightforward, based on the response to a direct questionnaire item. ${ }^{5,6}$ For pregnant women, the procedure is more complicated, because demand for contraception at the survey date is a matter of whether or not the current pregnancy was wanted, and in some countries this information was not gathered. Where information on the wantedness of the current pregnancy is provided by both surveys, ${ }^{7}$ a pregnant woman is classified as wanting no additional children if her pregnancy at the time of the survey was unwanted and if she did not desire another child after the one she was carrying. Where this information is not provided by both surveys, a pregnant woman is classified as wanting no additional children if her number of living children was equal to or greater than her desired number of children and if she did not desire another child after the one she was carrying.

The difference between the actual and ideal number of children is constructed as the simple arithmetical difference between the two variables (actual minus ideal). ${ }^{8}$ This difference is interpreted as an indicator of the extent to which desired fertility has been attained. The closer the absolute difference is to zero, the closer is the agreement between desired and achieved fertility. A negative number indicates that the desired fertility is yet to be attained, whereas a positive number indicates that desired fertility has been exceeded. Where a numeric value for the ideal number of children is not provided, a value is imputed. ${ }^{9}$ For convenience in this paper, the shorthand label "actual-ideal gap" is used for this variable. 
Including two fertility-preference variables - the desire for additional children, and the actual-ideal gap - is a departure from most recent research, where the practice has been to rely entirely on the first variable. Controlling for the desire for additional children, which is a simple dichotomy, the actual-ideal gap is considered to capture the strength of the desire to avoid pregnancy. Consistent with this interpretation, among those who indicate that they want no additional children, those who have attained or exceeded their ideal family size are more likely to use contraceptives in virtually every survey analyzed in this paper. One issue addressed in the empirical analysis is the extent to which the actual-ideal gap increases the overall explanatory power of fertility preferences, and, further, whether the marginal gain from including the actual-ideal gap varies by social factors such as stage of fertility transition and region.

The primary aim in this analysis is to determine the extent to which changes in fertility preferences can account for changes in contraceptive prevalence. To accomplish this, a regression-decomposition approach is explored. (see Althauser and Wigler 1972; Iams and Thornton 1975; and Firebaugh 1996.) Several previous studies have used essentially the same methodology in regional (Castro-Martin and Njogu 1994) and country-specific (Njogu 1991) studies of contraceptive change. In separate estimations for each survey, contraceptive use is regressed on the two fertility-preference variables specified above. ${ }^{10}$

$$
\begin{aligned}
& \mathrm{U}_{1}=\mathrm{a}_{1}+\mathrm{b}_{1} \mathrm{P}_{1}+\mathrm{e}_{1} \\
& \mathrm{U}_{2}=\mathrm{a}_{2}+\mathrm{b}_{2} \mathrm{P}_{2}+\mathrm{e}_{2},
\end{aligned}
$$

where $U$ is an indicator of contraceptive use ( $1=$ use, $0=$ nonuse $)$, $a$ is the regression intercept, $b$ are the coefficients for the effects of $P, P$ are indicators of fertility preferences, $e$ is the regression disturbance, and 1,2 denote first and second survey, respectively.

Equations $1 \mathrm{a}$ and $1 \mathrm{~b}$ can be combined in an expression for change in mean levels of use (that is, contraceptive prevalence) between the two dates:

$$
\underline{\mathrm{U}}_{2}-\underline{\mathrm{U}}_{1}=\left(\mathrm{a}_{2}-\mathrm{a}_{1}\right)+\left(\mathrm{b}_{2} \underline{\mathrm{P}}_{2}-\mathrm{b}_{1} \underline{\mathrm{P}}_{1}\right)
$$

where the underscore denotes a mean value. 
For the purposes of decomposition, equation (2) is rearranged and expanded

$$
\underline{\mathrm{U}}_{2}-\underline{\mathrm{U}}_{1}=\left(\mathrm{a}_{2}-\mathrm{a}_{1}\right)+\underline{\mathrm{P}}\left(\mathrm{b}_{2}-\mathrm{b}_{1}\right)+\underline{\mathrm{b}}\left(\underline{\mathrm{P}}_{2}-\underline{\mathrm{P}}_{1}\right)
$$

or

$$
\Delta \underline{\mathrm{U}}=\Delta \mathrm{a}+\underline{\mathrm{P}} \Delta \mathrm{b}+\underline{\mathrm{b}} \Delta \mathrm{P},
$$

where $\Delta$ indicates a first difference.

Change is now decomposed in terms of three components: (i) change in the intercepts $[\Delta \mathrm{a}]$; (ii) change in the coefficient (or "effect") of preferences $[\Delta b]$, weighted by the average composition $[\mathrm{P}]$; and, (iii) change in composition of women in terms of preferences $[\Delta P]$, weighted by the average coefficient $[\underline{b}]$. The first two components together comprise the total contribution of changes in coefficients. Any one of the components can be positive or negative in sign, but by definition, they must sum to the total amount of change in $\underline{\underline{U}}$ (that is, to 100 percent if the decomposition is given as a percent).

Having obtained these decomposition results, the observed change in contraceptive prevalence can be expressed as the simple sum of two components: changes in fertility preferences and changes in the effects of preferences on use (that is, the regression coefficients). ${ }^{11}$ Following the terminology of classic demographic decomposition (Kitagawa 1955), the first component is labeled "composition" and the second component "rates." Contraceptive prevalence can change as a result of either mechanismchanging preference structures, or changing propensity to use within preference categories (much of which can be regarded as changes in the "implementation of preferences"12). Either can account for a relatively small or large part of the observed change in prevalence.

\section{RESULTS}

\section{Trends in Contraceptive Use and Fertility Preferences}

For each country, Table 1 shows the dates of the two surveys and the percentage of currently married women aged 15-44 using contraceptives at the time of each survey. In all 22 countries, contraceptive prevalence increased during the intersurvey years. The highest percentage-point increase is found in Bangladesh (41 points), followed by Thai- 
land and Peru (32 points), Dominican Republic (30 points), Indonesia and Colombia (28 points), and Sri Lanka (27 points). At the other extreme, countries with less than a ten percentage-point increase are Yemen (7 points), Côte d'Ivoire and Senegal (8 points), and Brazil (9 points). Note that the length of the intersurvey period differs among countries, and this difference accounts for some of the variability in the increase in prevalence, although, in fact, some of the larger increases occur over relatively short periods (for example, in Thailand and Sri Lanka).

Summary statistics for fertility-preference variables are shown in Table 2. The indicators shown are: the percentage of women wanting no additional children, the mean ideal number of children, the mean actual-ideal gap, and the percentage of women for whom the actual number of children equals or exceeds their ideal. With only a few exceptions, all indicators suggest that the demand for fertility limitation increased during the intersurvey period. The largest percentage-point increase in the desire for no additional children is Kenya (32 points), followed by Nepal (25 points), and Ghana (19 points). These countries were at the onset of transition at the time of the first survey. Half of the 22 countries recorded less than a ten percentage-point increase in the desire to stop childbearing: Colombia, Philippines, and Senegal (4 points), Brazil (5 points), Peru and Thailand (7 points), Egypt and Paraguay (8 points), Dominican Republic (9 points), and Uganda and Indonesia (9.7 and 9.8, respectively). Two of these countries were in the early stages of transition in the period under observation (Uganda and Senegal), and the rest were at later stages.

Table 2 also shows that in all countries except Yemen, the ideal number of children declined between the two surveys, and the difference between living and ideal number of children became more positive in all countries except the Philippines, Sri Lanka, and Thailand. Moreover, the percentage of women for whom the actual number of children exceeds the ideal increased in all countries except the three Asian countries just mentioned. (Note that in these three countries, the increases in the proportion desiring no additional children are modest.) In general, these patterns are consistent with increases in the percentage desiring no additional children. What is especially striking about the trends in the ideal number of children (and, accordingly, the actual-ideal gap) is the magnitude of the decline in sub-Saharan Africa, exceeding one child in all five 
Table 2 Percentage of currently married women aged 15-44 wanting no more children, mean ideal number of children, mean actual-ideal gap, and the percentage of women for whom their actual number of living children equals or exceeds their ideal, 22 countries

\begin{tabular}{|c|c|c|c|c|}
\hline $\begin{array}{l}\text { Region/country/ } \\
\text { dates of surveys }\end{array}$ & $\begin{array}{c}\text { Percent who } \\
\text { want no more }\end{array}$ & $\begin{array}{c}\text { Mean ideal } \\
\text { number } \\
\text { of children }\end{array}$ & $\begin{array}{c}\text { Actual-ideal }^{a} \\
\text { number } \\
\text { of children }\end{array}$ & $\begin{array}{c}\text { Percent for } \\
\text { whom actual } \\
\text { number equals } \\
\text { or exceeds idea }\end{array}$ \\
\hline \multicolumn{5}{|c|}{ Sub-Saharan Africa } \\
\hline \multicolumn{5}{|l|}{ Côte d'Ivoire } \\
\hline 1980 & 3.1 & 8.1 & -5.3 & 3.5 \\
\hline 1994 & 14.5 & 6.0 & -2.8 & 18.8 \\
\hline \multicolumn{5}{|l|}{ Ghana } \\
\hline 1979 & 8.0 & 6.0 & -3.1 & 9.9 \\
\hline 1993 & 27.3 & 4.8 & -1.9 & 25.7 \\
\hline \multicolumn{5}{|l|}{ Kenya } \\
\hline 1978 & 11.5 & 7.0 & -3.2 & 17.4 \\
\hline 1993 & 43.0 & 4.0 & -0.3 & 51.1 \\
\hline \multicolumn{5}{|l|}{ Senegal } \\
\hline 1986 & 14.5 & 7.1 & -4.2 & 14.2 \\
\hline 1997 & 18.9 & 5.8 & -2.6 & 23.2 \\
\hline \multicolumn{5}{|l|}{ Uganda } \\
\hline 1988 & 15.0 & 6.7 & -3.5 & 15.1 \\
\hline 1995 & 24.7 & 5.6 & -2.5 & 20.1 \\
\hline \multicolumn{5}{|c|}{ North Africa and West Asia } \\
\hline \multicolumn{5}{|l|}{ Egypt } \\
\hline 1980 & 46.4 & 4.0 & -1.0 & 45.6 \\
\hline 1995 & 54.5 & 2.9 & 0.0 & 61.6 \\
\hline \multicolumn{5}{|l|}{ Morocco } \\
\hline 1980 & 31.6 & 4.8 & -1.2 & 39.0 \\
\hline 1995 & 42.6 & 3.8 & -0.5 & 48.0 \\
\hline \multicolumn{5}{|l|}{ Tunisia } \\
\hline 1978 & 37.8 & 4.1 & -0.5 & 48.4 \\
\hline 1988 & 52.4 & 3.5 & -0.2 & 54.3 \\
\hline \multicolumn{5}{|l|}{ Turkey } \\
\hline 1978 & 49.9 & 3.0 & -0.2 & 55.2 \\
\hline 1993 & 61.3 & 2.4 & 0.1 & 66.2 \\
\hline \multicolumn{5}{|l|}{ Yemen } \\
\hline 1979 & 13.6 & 5.3 & -2.7 & 17.1 \\
\hline 1991 & 29.4 & 5.5 & -1.5 & 35.8 \\
\hline
\end{tabular}


Table 2 (continued)

\begin{tabular}{|c|c|c|c|c|}
\hline $\begin{array}{l}\text { Region/country/ } \\
\text { dates of surveys }\end{array}$ & $\begin{array}{c}\text { Percent who } \\
\text { want no more }\end{array}$ & $\begin{array}{c}\text { Mean ideal } \\
\text { number } \\
\text { of children }\end{array}$ & $\begin{array}{c}\text { Actual-ideal }^{\mathrm{a}} \\
\text { number } \\
\text { of children }\end{array}$ & $\begin{array}{c}\text { Percent for } \\
\text { whom actual } \\
\text { number equals } \\
\text { or exceeds ideal }\end{array}$ \\
\hline \multicolumn{5}{|c|}{ South and Southeast Asia } \\
\hline \multicolumn{5}{|l|}{ Bangladesh } \\
\hline 1976 & 56.8 & 3.8 & -0.8 & 45.1 \\
\hline 1996 & 69.5 & 2.5 & -0.1 & 60.1 \\
\hline \multicolumn{5}{|l|}{ Indonesia } \\
\hline 1976 & 30.3 & 4.2 & -1.4 & 33.2 \\
\hline 1993 & 40.1 & 2.8 & -0.5 & 47.6 \\
\hline \multicolumn{5}{|l|}{ Nepal } \\
\hline 1976 & 25.2 & 4.0 & -1.6 & 33.0 \\
\hline 1996 & 50.4 & 2.9 & -0.2 & 56.8 \\
\hline \multicolumn{5}{|l|}{ Philippines } \\
\hline 1978 & 45.5 & 4.3 & -0.5 & 50.0 \\
\hline 1998 & 49.5 & 3.4 & -0.5 & 49.5 \\
\hline \multicolumn{5}{|l|}{ Sri Lanka } \\
\hline 1975 & 49.6 & 3.7 & -0.4 & 54.3 \\
\hline 1987 & 61.7 & 3.0 & -0.4 & 53.1 \\
\hline \multicolumn{5}{|l|}{ Thailand } \\
\hline 1975 & 49.3 & 3.6 & -0.5 & 49.9 \\
\hline 1987 & 56.5 & 2.7 & -0.5 & 49.9 \\
\hline \multicolumn{5}{|l|}{ Latin America } \\
\hline \multicolumn{5}{|l|}{ Brazil } \\
\hline 1986 & 61.8 & 3.0 & -0.3 & 50.9 \\
\hline 1996 & 66.7 & 2.5 & -0.1 & 60.4 \\
\hline \multicolumn{5}{|l|}{ Colombia } \\
\hline 1976 & 55.3 & 4.1 & -0.3 & 45.9 \\
\hline 1995 & 59.1 & 2.8 & 0.1 & 56.2 \\
\hline \multicolumn{5}{|c|}{ Dominican Republic } \\
\hline 1975 & 44.5 & 4.6 & -1.1 & 33.2 \\
\hline 1996 & 53.4 & 3.3 & -0.7 & 41.7 \\
\hline \multicolumn{5}{|l|}{ Mexico } \\
\hline 1977 & 45.2 & 4.4 & -0.6 & 43.7 \\
\hline 1987 & 58.2 & 3.3 & -0.2 & 53.9 \\
\hline \multicolumn{5}{|l|}{ Paraguay } \\
\hline 1979 & 25.4 & 5.1 & -1.8 & 20.2 \\
\hline 1990 & 33.6 & 4.4 & -1.2 & 30.4 \\
\hline \multicolumn{5}{|l|}{ Peru } \\
\hline 1978 & 53.5 & 3.7 & -0.2 & 51.9 \\
\hline 1996 & 60.6 & 2.6 & 0.2 & 61.7 \\
\hline
\end{tabular}

${ }^{a}$ Number of living children minus ideal number of children. 
countries and exceeding two children in Côte d'Ivoire and Kenya. The increases in the proportion desiring no additional children are also substantial in this region, but, in fact, the declines in ideal family size outpace these increases in the expressed desire to stop childbearing. In African societies, a precipitous decline in the total number of children desired appears to be a prominent feature of the early stages of fertility transition. As shown below, taking this decline into account is important for assessing the overall contribution of changes in fertility preferences to trends in contraceptive prevalence.

\section{Decomposition of Change in Contraception}

The data on trends in fertility preferences presented in Table 2 reveal increases in the desire to limit childbearing, some of them substantial, in all regions. Only in the Philippines and Thailand is any basis found for doubting that the desire to stop increased between the surveys. A strong individual-level relationship between fertility preferences and contraceptive behavior is well documented (Westoff and Bankole 1995; United Nations forthcoming). From this relationship, it follows that the increased demand for fertility limitation must have led to increases in contraceptive prevalence during the same intersurvey period. This is merely casual observation, however. The question can be articulated in a manner that leads to more precise quantification: What fraction of the increase in contraceptive use can be attributed to changes in fertility preferences?

The answer to this question is provided in Table 3, which presents the percentage decomposition of the increase in contraceptive prevalence into contributions of "composition" (that is, changes in fertility preferences) and "rates" (that is, changing rates of use within categories of fertility preferences). The composition component is that portion of the increase in prevalence that can be attributed to decreased demand for children, whereas the rates component reflects increased implementation of preferences. A clear message emerges from Table 3: Increases in contraceptive prevalence are due overwhelmingly to increased rates of use within preference categories, not to changes in fertility preferences. The rates component accounts for more than 70 percent of the increase in contraceptive prevalence in 20 of the 22 countries, and for more than 80 percent in more than two-thirds of the countries. In only two countries does decreased demand for children (the composition component) account for more than one-fourth of the increase in prevalence (Ghana [39 percent] and Kenya [31 percent]). In three coun- 
Table 3 Decomposition of the change in contraceptive prevalence among currently married women aged 15-44, 22 countries

\begin{tabular}{|c|c|c|c|c|}
\hline \multirow{2}{*}{$\begin{array}{l}\text { Region/country/ } \\
\text { dates of surveys }\end{array}$} & \multirow{2}{*}{$\begin{array}{l}\text { Percentage-point } \\
\text { change in } \\
\text { contracepitve } \\
\text { prevalence }\end{array}$} & \multicolumn{2}{|c|}{ Contribution of } & \multirow[b]{2}{*}{ Total } \\
\hline & & Composition $^{\mathrm{a}}$ & Rates $^{\mathrm{b}}$ & \\
\hline \multicolumn{5}{|l|}{ Sub-Saharan Africa } \\
\hline Côte d'Ivoire, 1980, 1994 & 8.4 & 24.2 & 75.8 & 100.0 \\
\hline Ghana, 1979, 1993 & 10.6 & 39.2 & 60.8 & 100.0 \\
\hline Kenya, 1978, 1993 & 24.7 & 31.3 & 68.7 & 100.0 \\
\hline Senegal, 1986, 1997 & 7.9 & 24.9 & 75.1 & 100.0 \\
\hline Uganda, 1988, 1995 & 10.0 & 16.2 & 83.8 & 100.0 \\
\hline \multicolumn{5}{|l|}{ North Africa and West Asia } \\
\hline Egypt, 1980, 1995 & 24.6 & 19.4 & 80.6 & 100.0 \\
\hline Morocco, 1980, 1995 & 21.9 & 17.9 & 82.1 & 100.0 \\
\hline Tunisia, 1978, 1988 & 18.6 & 25.2 & 74.8 & 100.0 \\
\hline Turkey, 1978, 1993 & 23.0 & 17.7 & 82.3 & 100.0 \\
\hline Yemen, 1979, 1991 & 7.2 & 18.8 & 81.2 & 100.0 \\
\hline \multicolumn{5}{|l|}{ South and Southeast Asia } \\
\hline Bangladesh, 1976, 1996 & 40.8 & 13.5 & 86.5 & 100.0 \\
\hline Indonesia, 1976, 1993 & 28.3 & 13.0 & 87.0 & 100.0 \\
\hline Nepal, 1976, 1996 & 25.6 & 24.5 & 75.5 & 100.0 \\
\hline Philippines, 1978, 1998 & 10.0 & 13.8 & 86.2 & 100.0 \\
\hline Sri Lanka, 1975, 1987 & 27.0 & 15.2 & 84.8 & 100.0 \\
\hline Thailand, 1975, 1987 & 31.8 & 8.8 & 91.2 & 100.0 \\
\hline \multicolumn{5}{|l|}{ Latin America } \\
\hline Brazil, 1986, 1996 & 9.3 & 12.1 & 87.9 & 100.0 \\
\hline Colombia, 1976, 1995 & 28.2 & 3.5 & 96.5 & 100.0 \\
\hline Dominican Republic, 1975, 1996 & 29.7 & 12.0 & 88.0 & 100.0 \\
\hline Mexico, 1977, 1987 & 21.8 & 16.5 & 83.5 & 100.0 \\
\hline Paraguay, 1979, 1990 & 10.8 & 17.8 & 82.2 & 100.0 \\
\hline Peru, 1978, 1996 & 31.6 & 3.6 & 96.4 & 100.0 \\
\hline
\end{tabular}

Note: For discussion of regression decomposition shown here, see text.

${ }^{a}$ Composition of the population according to fertility preferences: desire for additional births and the actual-ideal gap. $\quad \quad{ }^{b}$ Rates of use within fertility-preference categories. 
tries, decreased demand accounts for less than 10 percent of the increase in prevalence (Thailand [ 9 percent], Peru [4 percent], and Colombia [4 percent]). In short, increased implementation of fertility preferences, not changing demand for children, is the primary explanation for the increase in contraceptive use during this period of time in these countries.

As noted above, this analysis departs from most recent research in making use of two fertility-preference measures: the desire for another birth and the difference between the number of living children and the ideal number of children. The gain from including the actual-ideal gap is examined in Table 4, which shows the composition component in decompositions based solely upon the desire for another birth, solely on the actual-ideal gap, and based upon the two together (as in the decomposition in Table 3). ${ }^{13}$ Comparing the three columns in Table 4 , the countries are seen to be roughly evenly split into those where the desire to have no more children accounts for more of the increase in prevalence and those where the actual-ideal gap accounts for more of the increase in prevalence. Given that use of the "want no more" variable is conventional, the major question to ask here is what is gained by inclusion of the actual-ideal gap. Inclusion of this additional fertility-preference variable results in substantial increases in the composition component in the sub-Saharan African countries, more than doubling this component in Côte d'Ivoire and Senegal. Outside of sub-Saharan Africa, the inclusion of the actual-ideal gap also leads to substantial increases in the composition component in Egypt and Yemen. With the exception of Egypt, the countries where the actual-ideal gap makes a substantial contribution are countries near the onset of fertility transition, and most of these countries are also African. As noted above in the discussion of Table 2, sub-Saharan African societies are characterized by a sharp decline in ideal family size in the early stages of transition. Table 4 indicates that a failure to incorporate this aspect of fertility transition - unmistakably a feature of African transitions, and perhaps of the early stages of transitions in other regions as well-leads to a serious underestimation of the causal impact of changing fertility preferences.

The finding that change in prevalence is due mainly to changing rates of use within preference categories is examined in more detail in Table 5. This table shows trends in contraceptive prevalence separately for two fertility-preference categories 
Table 4 Percentage of the change in contraceptive prevalence due to changes in fertility preferences among currently married women aged 15-44, 22 countries

\begin{tabular}{lccc}
\hline & \multicolumn{3}{c}{ Percentage of change in prevalence due to } \\
\cline { 2 - 4 } $\begin{array}{l}\text { Region/country/ } \\
\text { dates of surveys }\end{array}$ & $\begin{array}{c}\text { Desire to stop } \\
\text { childbearing alone }\end{array}$ & $\begin{array}{c}\text { Actual-ideal } \\
\text { gap alone }\end{array}$ & $\begin{array}{c}\text { Desire to stop and } \\
\text { actual-deal gap }\end{array}$ \\
\hline Sub-Saharan Africa & & & \\
Côte d'Ivoire, 1980, 1994 & 9.2 & 23.9 & 24.2 \\
Ghana, 1979, 1993 & 25.2 & 33.5 & 39.2 \\
Kenya, 1978, 1993 & 24.4 & 27.0 & 31.3 \\
Senegal, 1986, 1997 & 4.5 & 27.9 & 24.9 \\
Uganda, 1988, 1995 & 10.8 & 16.6 & 16.2 \\
North Africa and West Asia & & & \\
Egypt, 1980, 1995 & 13.2 & 29.5 & 19.4 \\
Morocco, 1980, 1995 & 14.7 & 16.2 & 17.9 \\
Tunisia, 1978, 1988 & 25.3 & 12.7 & 25.2 \\
Turkey, 1978, 1993 & 18.6 & 7.1 & 17.7 \\
Yemen, 1979, 1991 & 12.3 & 16.4 & 18.8 \\
South and Southeast Asia & & & \\
Bangladesh, 1976, 1996 & 12.6 & 6.4 & 13.5 \\
Indonesia, 1976, 1993 & 11.9 & 20.5 & 13.0 \\
Nepal, 1976, 1996 & 22.0 & 19.6 & 24.5 \\
Philippines, 1978, 1998 & 13.6 & -0.1 & 13.8 \\
Sri Lanka, 1975, 1987 & 17.2 & 0.4 & 15.2 \\
Thailand, 1975, 1987 & 8.7 & 0.4 & 8.8 \\
Latin America & & & 12.5 \\
Brazil, 1986, 1996 & 13.6 & 3.6 & 16.5 \\
Colombia, 1976, 1995 & 3.9 & 2.2 & 3.6 \\
Dominican Republic, 1975, 1996 & 12.0 & 4.8 & \\
Mexico, 1977, 1987 & 16.6 & 5.6 & \\
Paraguay, 1979, 1990 & 16.2 & 11.7 & \\
Peru, 1978, 1996 & 5.0 & 2.1 & \\
\hline
\end{tabular}


Table 5 Adjusted percentage of currently married women aged 15-44 practicing contraception, by their desire for another birth, 22 countries

\begin{tabular}{|c|c|c|c|c|}
\hline $\begin{array}{l}\text { Region/country/ } \\
\text { dates of surveys }\end{array}$ & $\begin{array}{c}\text { Want more } \\
\text { children }\end{array}$ & $\begin{array}{c}\text { Want no more } \\
\text { children }\end{array}$ & $\begin{array}{c}\text { Absolute } \\
\text { difference }\end{array}$ & $\begin{array}{r}\text { Log odds } \\
\text { difference }\end{array}$ \\
\hline \multicolumn{5}{|c|}{$\begin{array}{l}\text { Sub-Saharan Africa } \\
\text { a }\end{array}$} \\
\hline \multicolumn{5}{|l|}{ Côte d'Ivoire } \\
\hline 1980 & 2.8 & 8.1 & 5.3 & 1.1 \\
\hline 1994 & 10.5 & 15.3 & 4.8 & 0.4 \\
\hline \multicolumn{5}{|l|}{ Ghana } \\
\hline 1979 & 9.0 & 16.4 & 7.4 & 1.7 \\
\hline 1993 & 17.3 & 27.1 & 9.8 & 0.6 \\
\hline \multicolumn{5}{|l|}{ Kenya } \\
\hline 1978 & 5.3 & 16.0 & 10.7 & 1.2 \\
\hline 1993 & 19.8 & 45.8 & 26.0 & 1.2 \\
\hline \multicolumn{5}{|l|}{ Senegal } \\
\hline 1986 & 4.1 & 6.7 & 2.6 & 0.5 \\
\hline 1997 & 11.9 & 14.6 & 2.7 & 0.2 \\
\hline \multicolumn{5}{|l|}{ Uganda } \\
\hline 1988 & 3.0 & 9.1 & 6.1 & 1.2 \\
\hline 1995 & 10.5 & 24.1 & 13.6 & 1.0 \\
\hline \multicolumn{5}{|c|}{ North Africa and West Asia } \\
\hline \multicolumn{5}{|c|}{ Egypt } \\
\hline 1980 & 11.5 & 35.7 & 24.2 & 1.5 \\
\hline 1995 & 22.4 & 71.5 & 49.1 & 2.2 \\
\hline \multicolumn{5}{|l|}{ Morocco } \\
\hline 1980 & 10.0 & 39.1 & 29.1 & 1.8 \\
\hline 1995 & 30.0 & 57.4 & 27.4 & 1.1 \\
\hline \multicolumn{5}{|l|}{ Tunisia } \\
\hline 1978 & 21.9 & 46.8 & 24.9 & 1.1 \\
\hline 1988 & 34.5 & 65.4 & 30.9 & 1.3 \\
\hline \multicolumn{5}{|l|}{ Turkey } \\
\hline 1978 & 26.7 & 56.2 & 29.5 & 1.3 \\
\hline 1993 & 31.9 & 84.4 & 52.5 & 2.4 \\
\hline \multicolumn{5}{|l|}{ Yemen } \\
\hline 1979 & 0.6 & 2.9 & 2.3 & 1.6 \\
\hline 1991 & 5.6 & 13.4 & 7.8 & 1.0 \\
\hline
\end{tabular}


Table 5 (continued)

\begin{tabular}{|c|c|c|c|c|}
\hline $\begin{array}{l}\text { Region/country/ } \\
\text { dates of surveys }\end{array}$ & $\begin{array}{l}\text { Want more } \\
\text { children }\end{array}$ & $\begin{array}{c}\text { Want no more } \\
\text { children }\end{array}$ & $\begin{array}{c}\text { Absolute } \\
\text { difference }\end{array}$ & $\begin{array}{r}\text { Log odds } \\
\text { difference }\end{array}$ \\
\hline \multicolumn{5}{|c|}{ South and Southeast Asia } \\
\hline \multicolumn{5}{|l|}{ Bangladesh } \\
\hline 1976 & 1.7 & 13.5 & 11.8 & 2.2 \\
\hline 1996 & 9.7 & 65.9 & 56.2 & 2.9 \\
\hline \multicolumn{5}{|l|}{ Indonesia } \\
\hline 1976 & 18.6 & 47.5 & 28.8 & 1.4 \\
\hline 1993 & 39.4 & 80.6 & 41.2 & 1.9 \\
\hline \multicolumn{5}{|l|}{ Nepal } \\
\hline 1976 & 0.6 & 5.3 & 4.7 & 2.2 \\
\hline 1996 & 6.0 & 49.4 & 43.4 & 2.7 \\
\hline \multicolumn{5}{|l|}{ Philippines } \\
\hline 1978 & 23.5 & 56.8 & 33.3 & 1.5 \\
\hline 1998 & 28.5 & 69.4 & 40.9 & 1.7 \\
\hline \multicolumn{5}{|l|}{ Sri Lanka } \\
\hline 1975 & 15.1 & 51.9 & 36.8 & 1.8 \\
\hline 1987 & 39.0 & 74.8 & 35.8 & 1.5 \\
\hline \multicolumn{5}{|l|}{ Thailand } \\
\hline 1975 & 18.2 & 53.7 & 35.5 & 1.7 \\
\hline 1987 & 40.3 & 88.2 & 47.9 & 2.4 \\
\hline \multicolumn{5}{|l|}{ Latin America } \\
\hline \multicolumn{5}{|l|}{ Brazil } \\
\hline 1986 & 45.5 & 79.8 & 34.3 & 1.6 \\
\hline 1996 & 44.4 & 90.7 & 46.3 & 2.5 \\
\hline \multicolumn{5}{|l|}{ Colombia } \\
\hline 1976 & 32.5 & 50.7 & 18.2 & 0.8 \\
\hline 1995 & 44.9 & 88.2 & 43.3 & 2.2 \\
\hline \multicolumn{5}{|c|}{ Dominican Republic } \\
\hline 1975 & 17.9 & 52.8 & 34.9 & 1.6 \\
\hline 1996 & 34.9 & 87.8 & 52.9 & 2.6 \\
\hline \multicolumn{5}{|l|}{ Mexico } \\
\hline 1977 & 22.2 & 45.5 & 23.3 & 1.1 \\
\hline 1987 & 34.6 & 68.7 & 34.1 & 1.4 \\
\hline \multicolumn{5}{|l|}{ Paraguay } \\
\hline 1979 & 35.9 & 46.4 & 10.5 & 0.4 \\
\hline 1990 & 39.2 & 69.5 & 30.3 & 1.3 \\
\hline \multicolumn{5}{|l|}{ Peru } \\
\hline 1978 & 23.6 & 42.1 & 18.5 & 0.9 \\
\hline 1996 & 47.1 & 76.2 & 29.1 & 1.3 \\
\hline
\end{tabular}

Note: Percentages are adjusted through logistic regression analysis. The other independent variable is the actual-ideal gap. 
(women who want more children and those who want no more). Consistent with the predominance of the rates component in the decompositions in Table 3, in most countries contraceptive use increases substantially in both preference categories. Taking the analysis a step further, we can ask whether the increase in use tends to be sharper in one category as compared with the other (or, phrased differently, whether the differential in use between preference categories widens or narrows over time). The answer depends on the measure used for the comparison. If the measure is simply percentages (that is, the contraceptive prevalence rates), the increases are generally larger in the "want no more" category, resulting in a widening over time of the differential between the "want more" and "want no more" categories (exceptions are Côte d'Ivoire, Morocco, and Sri Lanka) (see column 3 of Table 5). However, percentage-point differences do not adjust for the floors and ceilings in the contraceptive prevalence rate, which, of course, cannot fall below 0 percent or exceed 100 percent. A common strategy for coping with this problem is to apply the logit transform. ${ }^{14}$ Once we apply this transform, no dominant pattern emerges: The differential widens in 14 countries, reflecting more rapid increase in contraceptive use in the "want no more" category, and narrows in seven countries, reflecting a faster rate of increase in the "want more" category (see column 4 of Table 5). In Kenya, the rate of increase is roughly the same in the two preference categories.

\section{DISCUSSION}

The major finding of this research is that the substantial increases in contraceptive prevalence in the period since the 1970s in Latin America, Asia, and Africa were less the result of increased demand for family-size limitation and more the result of satisfaction of existing demand. This finding is clearly at odds with that of those who assign a dominant causal role to changes in fertility desires, and it certainly refutes the more extreme view that increased implementation of existing preferences has made only a trivial contribution to the fertility declines of the past three decades (Pritchett 1994). In this respect, the empirical results presented in this paper are more compatible with a supply-side than a demand-side interpretation, although a qualification must be placed on this judgment: The more complete implementation of preferences reflected in the rates component may be the result of improved supply of contraceptives, but it might 
also be a consequence of the lowering of nonaccess costs of using contraceptives (the cultural, social, and psychic costs). Population policies and programs may have a great deal or little to do with the lowering of nonaccess costs. Social diffusion processes operating relatively independently of explicit policies and programs can make a substantial contribution to the lowering of such costs (Rosero-Bixby and Casterline 1993; Bongaarts and Watkins 1996; Montgomery and Casterline 1998).

We must be cautious about extending these findings beyond the specific historical period and regions on which they are based. Most fertility transitions, if observed over the entire period from pre- to post-transition, are probably characterized by large declines in desired fertility (on the order of two or more births), without which it would be difficult to imagine a fertility decline of anything like the same magnitude. Certainly, fertility declines in sub-Saharan Africa, if they are to proceed as far as replacementlevel fertility (or, to be more conservative, to total fertility rates of three births or fewer per woman), would appear to require substantial departures from pretransition desires for six or more births on average. By this reasoning, substantial declines in the demand for children must be considered a fundamental driving force of fertility transition, and, indeed, they are the necessary condition for fertility transition.

In making this argument, however, a great risk is run of exaggerating both the causal centrality of a decline in the demand for children and the magnitude of such declines, especially if the measure is number of children surviving to adulthood rather than number of births (Wilson and Airey 1999; Cleland 1999). A modest number of children surviving to adulthood may have been the desired outcome in most societies for most of human history. If so, pre- and post-transition societies may differ less in the prevalence of aspirations for large families than has been imagined, and fertility transition is less accurately portrayed as a fundamental re-valuation of children and more as a process of replacing those who have died rather than as an unintentional mechanism for limiting family size with contraception (and other fertility-inhibiting behaviors, such as induced abortion and delayed marriage). According to this argument, demand for surviving children changes less than might be imagined over the course of fertility transition (at the same time as the demand for live births might decline substantially). Although some of the central tenets of the demand-side explanation can be reconciled with this argument, it describes a historical process that consists at its core of a shift toward 
increasing reliance on contraception for the achievement of family-size desires; that is, fertility transition is driven by increasing implementation of fertility preferences through contraceptive practice. The empirical results shown here, themselves specific to poor countries in the latter decades of the twentieth century, are consistent with this more sweeping depiction of the forces underlying fertility transition.

Whether or not inferences can be made from the results presented in this paper to larger questions about the nature of fertility transition, the results indicate that significant increases in contraceptive prevalence can occur without accompanying changes in fertility desires. This finding is an important empirical verification of the premise that has justified population policy and the development of family planning programs in many countries during the past three decades, namely that unsatisfied demand for contraception is widespread and that satisfying this demand will lead to large increases in contraceptive prevalence. At the same time, changes in fertility desires cannot be dismissed entirely, as these account, on average, for one-fifth of the observed increase in prevalence in the countries and period under examination. This fraction is relatively larger in those societies with the highest fertility, in particular in sub-Saharan African societies. Here, more complete implementation of existing fertility preferences will not, in itself, lead to high levels of contraceptive prevalence. Rather, in these societies, transformation of fertility-preference structures toward much smaller family-size desires will be an additional and necessary component of fertility transition, and the design of population policies and family planning programs should be informed by this fact.

\section{Notes}

1 Several excellent recent single-country studies do not estimate directly the contribution of fuller implementation of preferences; rather they demonstrate that changes in factors associated with the demand for children, such as schooling, structure of the economy, and child survival, appear to account for most of the observed change in contraception and/or fertility: For Indonesia in the 1980s, see Gertler and Molyneaux 1994; for Iran from the 1950s to the 1970s, see Raftery et al. 1995. These same factors can also influence the implementation of preferences, however, and thus these studies do not address directly the question of how much of the fertility change can be attributed solely to changes in fertility 
desires. In a study of Prussia in the late nineteenth century, Lee et al. (1994) conclude that although reductions in the demand for children account for the largest part of the fertility decline, readiness to practice contraception also makes a substantial contribution (accounting for one-sixth to one-third of the decline, under various specifications). The authors' calculations rely on indirect indicators of both the readiness to use contraceptives and the demand for children. In a less formal, more interpretative analysis of the countries of South Asia, Shah and Cleland (1993) argue that considerable unsatisfied demand for fertility regulation exists in these societies, and hence, in the short term, substantial fertility decline could occur with little or no change in fertility desires.

2 Several countries that might appear to satisfy these criteria are not included either because one of the data sets is not available for analysis (Jordan), because a key variable is measured differently in the two surveys (Cameroon-fertility preferences), or because examination of the data raises serious concerns about the validity of the measurement of a key variable (Bolivia-fertility preferences).

3 In Indonesia and Yemen, the DHS covered more regions than did the WFS. Those regions not sampled in the WFS are excluded here. In Indonesia, the DHS sample is limited to the following provinces: DKI Jakarta, West Java, Central Java, DI Yogyarkarta, East Java, and Bali. In Yemen, the DHS sample is limited to the following governorates: Sana'a, Dhamar, Al Mahweet, Sa' dah (North), Taiz, Ibb (South), Hajjah, Hodiedah (West), Ma'arib, and Al Beida (East).

4 An exception is Senegal, where periodic abstinence was excluded from the list of contraceptive methods in the 1986 DHS. For consistency, abstinence is excluded from the list of methods in the 1997 DHS.

5 Women who are contraceptively sterilized, or whose husbands are sterilized, are classified as not wanting additional children. Those who are undecided about whether or not they want additional children-a small fraction in all surveys, the largest being 11 percent in the 1978 WFS in Kenya-are classified as wanting additional children. 

they wanted an additional child "soon." For comparability with this eccentric wording, in the 1996 DHS, women who state they want no more children are combined with women who want to delay the next birth for at least two years. (This procedure assumes that "soon" in the 1976 WFS means within two years.) In both Bangladesh surveys, therefore, the contrast is between those women who want another child soon and those women who want to postpone or stop childbearing.

7 This information is provided in the surveys for Bangladesh, Colombia, Dominican Republic, Egypt, Indonesia, Morocco, Peru, and Turkey.

8 Current pregnancies are excluded in figuring the actual number of children. This exclusion results in equivalent treatment of pregnant women on the two preference variables, as explained above; for a pregnant woman her desire for another child refers to the time when she became pregnant, rather than her desire for another child after the termination of her current pregnancy.

9 Ideal number of children is missing for some respondents, usually because the woman replied with a nonnumeric response (such as "whatever God wishes"). In about one-fourth (12) of the surveys, more than 10 percent of respondents gave a nonnumeric response. The highest proportion of nonnumeric responses is 43 percent in the 1979 WFS in Yemen. In about one-half of the surveys (22), fewer than 5 percent gave a nonnumeric response. In all these cases, the ideal number of children is imputed via a regression equation. For those women who gave a numeric response, ideal number of children is regressed on age, woman's and partner's years of schooling, rural-urban residence, and partner's occupation. The resulting regression equation is used to calculate a predicted ideal number of children for those women lacking a numeric response. The predicted value is rounded to the nearest integer.

10 Because contraception is represented by a binary variable - use and nonuselogistic regressions are estimated. The desire for an additional child is repre- 
sented by a dummy variable, and the difference between actual and ideal number of children is a continuous variable. Sampling weights are applied.

11 The decomposition methodology adopted for this analysis eliminates the interaction component present in some decomposition approaches by using as weights, in the calculation of the decomposition, averages of the values for the two surveys (Iams and Thornton 1975). See equation (3).

12 Increased rates of use among those who do not desire additional children represent increased implementation of stopping preferences. Increased rates of use among those who desire more children can reflect either increased implementation of spacing preferences or an increase in the fraction wishing to space; the two are mixed together in this analysis. Other research indicates, however, that birth-spacing preferences change little over the course of fertility transition, and hence in most countries increased rates of use among those who desire more children can be assumed to result mainly from increased implementation of spacing preferences.

13 Because a regression decomposition is used, the composition component can be calculated on the basis of one of the two measures to exceed the composition component based on the two measures, an outcome that, on the face of it, seems illogical. This outcome occurs in 10 of 44 comparisons in Table 4, but in only four of these does it amount to as much as a two percentage-point discrepancy. These discrepancies occur when the decrease in the absolute value of one regression coefficient (for example, desire for additional children) is not compensated for by the additional contribution to the decomposition of changes in the other variable (for example, actual-ideal gap).

14 The logit transform is the natural logarithm of the odds of using:

$$
\ln \left(\mathrm{U}_{\mathrm{ps}} /\left(1-\mathrm{U}_{\mathrm{ps}}\right)\right)
$$

where $\mathrm{U}$ is the proportion using contraception, $\mathrm{p}$ denotes preference category ("want more" or "want no more"), and s denotes survey (first or second survey). 
This transform is applied to the proportion practicing contraception in each preference category for each survey. The difference between preference categories is then calculated for each survey.

\section{References}

Althauser, Robert P. and Michael Wigler. 1972. "Standardization and component analysis." Sociological Methods and Research 1(1): 97-135.

Bankole, Akinrinola and Charles F. Westoff. 1998. "The consistency and validity of reproductive attitudes: Evidence from Morocco." Journal of Biosocial Science 30(4): 439-455.

Berelson, Bernard. 1966. "KAP studies on fertility." In Bernard Berelson (ed.) Family Planning and Population Programs. Chicago: University of Chicago Press. Pp. 665-668.

Bongaarts, John. 1992. “Do reproductive intentions matter?” International Family Planning Perspectives 18(3): 102-108.

_ 1993. "The supply-demand framework for the determinants of fertility: An alternative implementation." Population Studies 47(3): 437-456.

Bongaarts, John and Judith Bruce. 1995. "The causes of unmet need for contraception and the social content of services." Studies in Family Planning 26(2): 57-75.

Bongaarts, John and Susan Cotts Watkins. 1996. "Social interactions and contemporary fertility transitions." Population and Development Review 22(4): 639-682.

Caldwell, John, I.O. Orubuloye, and Pat Caldwell. 1992. "Fertility decline in Africa: A new type of transition?" Population and Development Review 18(2): 211-242.

Casterline, John B., Aurora E. Perez, and Ann E. Biddlecom. 1997. "Factors underlying unmet need for family planning in the Philippines." Studies in Family Planning 28(3): 173-191.

Castro-Martin, Teresa and Wamucii Njogu. 1994. "A decade of change in contraceptive behaviour in Latin America: A multivariate decomposition." Population Bulletin of the United Nations 36: 81-109. 
Cleland, John. 1999. "Restating the obvious: The effects of improved survival on fertility." Revision of paper presented at the conference on Global Fertility Transition, Bellagio, Italy, May 1998. London: London School of Hygiene and Tropical Medicine.

Cleland, John and Chris Wilson. 1987. "Demand theories of fertility decline: An iconoclastic view." Population Studies 41(1): 5-30.

Davis, Kingsley. 1963. "The theory of change and response in modern demographic history." Population Index 29 (October): 345-366.

De Silva, W. Indralal. 1991. "Consistency between reproductive preferences and behavior: The Sri Lankan experience.” Studies in Family Planning 22(3): 188-197.

Easterlin, Richard A. and Eileen M. Crimmins. 1985. The Fertility Revolution: A Supply-Demand Analysis. Chicago: University of Chicago Press.

Firebaugh, Glenn. 1996. Analyzing Repeated Surveys. Thousand Oaks, CA: Sage Publications.

Freedman, Ronald. 1979. "Theories of fertility decline: A reappraisal." Social Forces 58(1): $1-17$.

Gertler, Paul J. and John W. Molyneaux. 1994. "How economic development and family planning programs combined to reduce Indonesian fertility." Demography 31(1): 33-63.

Hauser, Philip M. 1967. "Family planning and population programs.” Demography 4(1): 397-414.

Hermalin, Albert I., Ronald Freedman, Te-Hsiung Sun, and Ming-Cheng Chang. 1979. "Do intentions predict fertility? The experience in Taiwan, 1967-74." Studies in Family Planning 10(3): 75-95.

Hirschman, Charles. 1994. "Why fertility changes." Annual Review of Sociology 20: 203-233.

Iams, Howard M. and Arland Thornton. 1975. "Decomposition of differences: A cautionary note." Sociological Methods and Research 3(3): 341-351. 
Kitigawa, Evelyn M. 1955. "Components of a difference between two rates." Journal of the American Statistical Association 50(10): 1,168-1,194.

Knodel, John and Etienne van de Walle. 1979. "Lessons from the past: Policy implications of historical fertility studies." Population and Development Review 5(2): 217-246.

Lee, Ronald D., Patrick R. Galloway, and Eugene A. Hammel. 1994. "Fertility decline in Prussia: Estimating influences on supply, demand, and degree of control." Demography 31(2): 347-373.

Mauldin, W. Parker 1965. "Fertility studies: Knowledge, attitude, and practice." Studies in Family Planning 7: 1-10.

Montgomery, Mark R. and John B. Casterline. 1998. "Social Networks and the Diffusion of Fertility Control.” Policy Research Division Working Paper No. 119. New York: Population Council.

Njogu, Wamucii. 1991. "Trends and determinants of contraceptive use in Kenya." Demography 28(1): 83-99.

Notestein, Frank 1953. "Economic problems of population change." In Proceedings of the Eighth International Conference of Agricultural Economists. London: Oxford University Press. Pp. 13-31.

Poo Chang Tan, and Nai Peng Tey. 1994. "Do fertility intentions predict subsequent behavior? Evidence from Peninsular Malaysia." Studies in Family Planning 25(4): 222-231.

Pritchett, Lant H. 1994. "Desired fertility and the impact of population policies." Population and Development Review 20(1): 1-55.

Raftery, Adrian E., Steven M. Lewis, and Akbar Aghajanian. 1995. "Demand or ideation? Evidence from the Iranian marital fertility decline." Demography 32(2): 159-182.

Rosero-Bixby, Luis and John B. Casterline. 1993. "Modelling diffusion effects in fertility transition." Population Studies 47(1): 147-167. 
Shah, Iqbal H. and John G. Cleland. 1993. "High fertility in Bangladesh, Nepal, and Pakistan: Motives versus means." In Richard Leete and Iqbal Alam (eds.), The Revolution in Asian Fertility: Dimensions, Causes, and Implications. Oxford: Clarendon Press. Pp. 175-207.

United Nations. Forthcoming. Levels and Trends of Contraceptive Use as Assessed in 1999. New York: United Nations.

Westoff, Charles F. 1990. "Reproductive intentions and fertility rates." International Family Planning Perspectives 16(3): 84-89.

Westoff, Charles F. and Norman B. Ryder. 1977. "The predictive validity of reproductive intentions." Demography 14(4): 431-453.

Westoff, Charles F. and Akinrinola Bankole. 1995. Unmet Need: 1990-1994. Demographic and Health Surveys Comparative Studies No. 16. Calverton, MD: Macro International.

—_ 1999. "Trends in the demand for family limitation in developing countries." Princeton, NJ: Office of Population Research, Princeton University. Unpublished.

Wilson, Chris and Pauline Airey. 1999. "How can a homeostatic perspective enhance demographic transition theory?" Population Studies 53(2): 117-128. 


\title{
POLICY RESEARCH DIVISION WORKING PAPERS
}

\author{
Recent Back Issues
}

93 James F. Phillips, Fred N. Binka, Martin Adjuik, Alex Nazzar, and Kubaze Frank Adazu, "The determinants of contraceptive innovation: A case-control study of family planning acceptance in a traditional African society."

*94 John Bongaarts and Sajeda Amin, "Prospects for fertility decline and implications for population growth in South Asia."

95 Barbara S. Mensch and Cynthia B. Lloyd, "Gender differences in the schooling experiences of adolescents in low-income countries: The case of Kenya."

96 Martin Brockerhoff and Ellen Brennan, "The poverty of cities in the developing world."

*97 Carol E. Kaufman, "Reproductive control in South Africa."

*98 John Bongaarts, "Trends in unwanted childbearing in the developing world."

99 Mary Arends-Kuenning, "How do family planning workers' visits affect women's contraceptive behavior in Bangladesh?"

100 Mark R. Montgomery and Cynthia B. Lloyd, "Excess fertility, unintended births, and children's schooling."

101 Mary Arends-Kuenning, "The equity and efficiency of doorstep delivery of contraceptives in Bangladesh."

*102 Sajeda Amin, Ian Diamond, Ruchira T. Naved, and Margaret Newby, "Transition to adulthood of female factory workers: Some evidence from Bangladesh."

*103 Margaret E. Greene and Ann E. Biddlecom, "Absent and problematic men: Demographic accounts of male reproductive roles."

104 Michael P. Todaro, "Urbanization, unemployment, and migration in Africa: Theory and policy."

105 Geoffrey McNicoll, "Population and poverty: A review and restatement."

* No longer available 
106 Sajeda Amin and Gilda Sedgh, "Incentive schemes for school attendance in rural Bangladesh.”

107 Martin Brockerhoff and Paul Hewett, "Ethnicity and child mortality in subSaharan Africa."

108 Ann E. Biddlecom and Bolaji M. Fapohunda, "Covert contraceptive use: Prevalence, motivations, and consequences."

109 John Bongaarts and Griffith Feeney, "On the quantum and tempo of fertility."

110 Barbara S. Mensch, Daniel Bagah, Wesley H. Clark, and Fred Binka, "The changing social environment for adolescents in the Kassena-Nankana District of northern Ghana: Implications for reproductive behavior."

111 Martin Brockerhoff and Ann Biddlecom, "Migration, sexual behavior, and HIV diffusion in Kenya."

112 Zeba A. Sathar and John B. Casterline, "The onset of fertility transition in $\mathrm{Pa}$ kistan."

113 Geoffrey McNicoll, "Government and fertility in transitional and post-transitional societies."

\footnotetext{
* No longer available
}

114 John Bongaarts, "Fertility and reproductive preferences in post-transitional societies."

115 Fiona Steele, Sajeda Amin, and Ruchira T. Naved, "The impact of an integrated micro-credit program on women's empowerment and fertility behavior in rural Bangladesh."

*116 Cynthia B. Lloyd, Barbara S. Mensch, and Wesley H. Clark, "The effects of primary school quality on the educational participation and attainment of Kenyan girls and boys."

117 Sajeda Amin and Cynthia B. Lloyd, "Women's lives and rapid fertility decline: Some lessons from Bangladesh and Egypt."

118 James F. Phillips and Mian Bazle Hossain, "The impact of family planning household service delivery on women's status in Bangladesh."

119 Mark R. Montgomery and John B. Casterline, "Social networks and the diffusion of fertility control." 
120 John Bongaarts, "The fertility impact of changes in the timing of childbearing in the developing world."

*121 James F. Phillips, Wendy L. Greene, and Elizabeth F. Jackson, "Lessons from community-based distribution of family planning in Africa."

122 Mark R. Montgomery, "Mortality decline and the demographic response: Toward a new agenda."

123 Mark R. Montgomery, Mary ArendsKuenning, and Cem Mete, "The quantity-quality transition in Asia."

124 Barbara S. Mensch, Wesley H. Clark, Cynthia B. Lloyd, and Annabel S. Erulkar, "Premarital sex and school dropout in Kenya: Can schools make a difference?"

125 John Bongaarts and Rodolfo A. Bulatao, "Completing the demographic transition."
126 Geoffrey McNicoll, "Population weights in the international order."

127 Cynthia B. Lloyd, Carol E. Kaufman, and Paul Hewett, "The spread of primary schooling in sub-Saharan Africa: Implications for fertility change."

128 John B. Casterline, "The onset and pace of fertility transition: National patterns in the second half of the twentieth century."

129 Mark R. Montgomery, Michele Gragnolati, Kathleen Burke, and Edmundo Paredes, "Measuring living standards with proxy variables."

130 Bamikale Feyisetan and John B. Casterline, "Fertility preferences and contraceptive change in developing countries."

* No longer available 